\title{
MICROWAVES APPLIED TO CARBOTHERMIC REDUCTION OF IRON ORE PELLETS
}

\author{
JUAN A. AGUILAR \\ IDALIA GOMEZ
}

Universidad Autónoma de Nuevo León, Facultad de Ingeniería Mecánica y Eléctrica

Apartado Postal 076"F", Cd. Universitaria, San Nicolás de los Garza, N.L. CP. 66450, México

Tel. (52+8) 329-40-20, Fax. (52+8) 376-45-14, (52+8)332-09-04

Juan Aguilar's e-mail: aaguilar@ccr.dsi.uanl.mx

Idalia Gómez's e-mail: lagomez@ccr.dsi.uanl.mx 


\begin{abstract}
Results of reducibility tests of reduction conducted on iron ore pellets with carbon are presented in this work. Work done is centered on reduction kinetics using carbon as reducing agent with conventional heat supply (heat transfer process) compared with reduction kinetics where heat is supplied by microwaves to the whole volume. Ore used in this work is called "Alzada" which has reducibility characteristics well known, and is often used as standard for comparison.
\end{abstract}

\title{
INTRODUCTION
}

Obtaining a metal from its oxide is a process called reduction, and to conduct this process we must provide energy to the system. The most common way is fire or electricity. There are some studies on microwave applications for supplying energy for non metallic transformations, but just lately microwaves are being applied to metals [Standish and Worner, 1990]; [Standish and Huang, 1991]. It is possible to visualize the reduction of iron ore with solid carbon as a system where carbon monoxide $(\mathrm{CO})$ is removed as fast as it is produced. In this work the importance of solid carbon in contact with the oxide is much smaller than the production of carbon monoxide from it by Boudouard reaction, which gives a $\mathrm{CO} / \mathrm{CO}_{2}$ mixture. According to thermodynamic properties of this reaction $(\mathrm{C}+$ $\mathrm{CO}_{2}=2 \mathrm{CO}$ ), above $1000^{\circ} \mathrm{C}$, it is possible to have an atmosphere of almost pure carbon monoxide. Necessary heat to conduct the reduction process is supplied in this case by microwaves, even when the product is a metal.

The objective of this work is to demonstrate that iron ore can absorb energy from microwaves. Therefore, it is possible to conduct the reduction process with microwaves as a power source.

\section{REDUCTION PROCESS}

Once carbon monoxide is produced by Boudouard reaction, the reduction of an iron ore pellet is divided in two steps [Bougdandy and Engell, 1971]:

a) Diffusion of $\mathrm{CO}$ through external reduced core.

b) Chemical reaction over the reduced core / oxide interphase. 
These steps correspond to a topochemical reduction following scheme on figure 1 which shows such condition.

Figure 1 shows a spherical pellet with three well defined reaction interphases. $r_{0}$ is the outside radius while $r_{1}, r_{2}$ and $r_{3}$ are respectively the interphases where reduction from wustite $(\mathrm{FeO})$ to metallic iron $(\mathrm{Fe})$, magnetite $\left(\mathrm{Fe}_{3} \mathrm{O}_{4}\right)$ to wustite and hematite $\left(\mathrm{Fe}_{2} \mathrm{O}_{3}\right)$ to magnetite are taking place. The reduction begins with the reduction of hematite to magnetite, this magnetite is then reduced to wustite and finally to metallic iron. The reactions for each stage are:

$$
\begin{gathered}
\mathrm{r}_{3}: \quad 3 \mathrm{Fe}_{2} \mathrm{O}_{3}+\mathrm{CO}=2 \mathrm{Fe}_{3} \mathrm{O}_{4}+\mathrm{CO}_{2} \\
\mathrm{r}_{2}: \quad \mathrm{Fe}_{3} \mathrm{O}_{4}+\mathrm{CO}=3 \mathrm{FeO}+\mathrm{CO}_{2} \\
\mathrm{r}_{1}: \quad \mathrm{FeO}+\mathrm{CO}=\mathrm{Fe}+\mathrm{CO}_{2}
\end{gathered}
$$

Normally chemical reaction and diffusion are both controlling [Tiwari and Bandyopadhyay, 1992] the process, but at high temperatures, above $800^{\circ} \mathrm{C}$, diffusion control becomes more important.

Figure 2 is an actual pellet reduced conventionally that shows a well defined interphase, the dark region at the center is wustite, the rest is metallic iron.

\section{EXPERIMENTAL PROCEDURE}

\section{Iron ore}

Iron ore for tests is coming in pellet shape from the "Alzada" mine in the mexican state of Colima, this material is widely used by some mexican steel corporation and has been tested previously [Aguilar, Fuentes and Viramontes, 1995]. Mean characteristics of this ore are presented in Table I.

\section{Sample preparation}

Several tests of carbothermic reduction were conducted to evaluate which was the best carbon/pellet ratio 
for performing the reduction. This ratio was 3.5 times the stoichiometric ratio (taking just the hematite in the pellet). Pellet was dried for three hours in a conventional oven at $300^{\circ} \mathrm{C}$. Carbon was obtained from electrodes of electric arc grinned to powder.

\section{Test description}

Carbothermic reduction tests with microwaves were conducted in a conventional microwave oven $(2450$ $\mathrm{MHz}, 800$ Watts), while conventional reduction tests were conducted in an electric resistance furnace at $1100^{\circ} \mathrm{C}$. Both pellet and carbon were placed inside a crucible made of pure aluminum oxide. High purity carbon was used to reduce the pellet.

One important aspect was the characterization of the oven, due to cavity was not uniformly full of microwaves we could not seat our sample at any place inside. After numerous tests we confirm that the microwave pattern is not uniform and then several tests were carried out to know the right place inside the oven for setting the crucible. Tests consisted in placing the crucible with the specimen inside the oven, madding a scan over the cavity, it is important to notice that the microwave pattern depends of the matter that is in the cavity, thus if we use a different material we have to search for the best place for placing it by checking where the highest energy input was obtained. According to the results of these tests for determining the best place for placing the crucible, radiation zone begins about $5 \mathrm{~cm}$ from the aperture and extends up to opposite wall. However, the highest energy input zone is located at $26 \mathrm{~cm}$ in front of the aperture and $6 \mathrm{~cm}$ from the bottom of the cavity (Figure 3). The oven was programmed for different times. When this time was reached, the specimen was removed and chemically analyzed. Kinetic diagrams (reduction degree against time) were constructed with this information. For reduction in a conventional furnace, it was heated until desire temperature was reached and stabilized. Crucibles with specimens were placed inside the furnace, and removed one by one.

In all cases, scanning electronic microscopy was employed to observe the specimens.

\section{Microwave heating procedure}

A single pellet was placed inside the microwave oven, at the place that previously we determined as the best. Temperature increased very rapidly, despite the radiation loss, in less than ten seconds it passed from room 
temperature to $800^{\circ} \mathrm{C}$ (Optical pyrometry).

A single pellet was placed over a bed carbon, so that one third of the pellet was under the carbon bed. Upper part (two thirds) was exposed to environment inside the oven. In this case temperature increased as it is described above, but carbon reaches temperatures over $980^{\circ} \mathrm{C}$. Temperature in the region between carbon and pellet was higher (we could not get data of this region because it is too small, but it was bright yellow). Rest of the pellet was colder (it was slightly red), but suddenly, at about twenty seconds of test, cold part got as red as carbon $\left(980^{\circ} \mathrm{C}\right)$.

One idea is that some $\mathrm{CO}$ from carbon bed covers the pellet (mainly hematite), and reduction from hematite to magnetite takes place. According to dielectric properties of magnetite and other research work [McGill, Walkiewicz and Symres, 1988], it absorbs more energy from microwaves, which could be one reason for temperature increasing. Besides, reduction from magnetite to wustite is exothermic.

Several tests over many materials were conducted to select one that was unaffected for the microwave field. From these tests, high purity aluminum oxide crucibles were choused. Explained tests (single pellet and single pellet in a bed) were conducted inside these crucibles with same results. Tests consist then, in placing the pellet over a small bed of carbon, and cover it until carbon/hematite radio is 3.5 .

\section{Dust processing}

Results obtained (that will discussed below) from the tests previously described, made necessary to conduct test on dust in order to justify some of our inferences that we applied to the pellet behavior exposed to a microwave field.

Tests were conducted with ferric oxide (hematite, reagent degree, 50 microns) dust in the same ratio (carbon/dust) and sample amount than for pellet test. The mixture of dust and carbon was placed inside the crucible and placed in the same position determinated for the pellet tests and conducted in the same manner.

\section{RESULTS AND DISCUSSION}

Once that explained tests were conducted and analyzed, it is possible to have a discussion about reduction degree, temperature estimation and factors affecting the reduction rate. 


\section{Reduction degree}

Summary of results of microwave tests are presented in Figure 4. This figure shows a solid curve which was generated with a validate computer model [Aguilar, 1994] simulating reduction with $\mathrm{CO}$ at $1100^{\circ} \mathrm{C}$, diamonds over the curve correspond to results of experiments conducted with carbon/hematite weight ratios of 3.5. In the same figure pluses show the results of the tests conducted conventionally (with the same carbon/hematite ratio), notice how these pluses fall over the curve generated by the model. This simulated curve is based upon a topochemical reduction model that accepts that temperature inside the pellet is almost constant. According to Okura and Maddox [1975] differences between border and center of the pellet are $25^{\circ} \mathrm{C}$ maximum when reduction was conducted with hydrogen. Considering that reduction with hydrogen is strongly endothermic, then in this case the differences will be smaller. This situation is in agree with other researchers [Bougdandy and Engell, 1971].

Experimental results for carbon/hematite weight ratios below 3.5 are not shown, but they exhibit limited reduction degree because the reducing agent amount is not enough. On the other hand, carbon/hematite weight ratios over 3.5 are very similar to those with 3.5 . Reason for explaining reduction stopped at $40 \%$ is an important conclusion that is discussed later.

\section{Temperature estimation}

To make a realistic comparison between microwave and conventional reduction we must estimate which is the temperature in the pellet while reduction is being conducted. There is no problem for having a kinetic curve for conventional reduction, because it is easy to measure temperatures in a conventional furnace. Besides, it is possible to use a validated model for describing reduction. Temperature measurement inside a microwave field is a challenge [Binner, 1993], thermocouples could be covered with a metal shield, but this disturbs the microwave pattern inside the cavity. Optical pyrometry here is more useful for this kind of applications, but it just gives surface temperatures. In this work temperature measurements were done with both, thermocouples and optical pyrometry. There were some problems with thermocouple, in first place, it was very hard to obtain a readable signal (values on the display were changing very fast), because microwaves were generating currents in the system. One solution for this was to stop the energy just for a moment, to have a data, and then continue the test (this is not very accurate because temperature changes too fast, so the test is being perturbed). The case of analogical gages is better, because at least it 
shows a range. Optical pyrometry shows better results in a way that it is easier to have measurement.

One way to estimate temperatures is to identify and analyze the different phases that are present in the pellet, and verify if they are melted or solid, and according with their properties estimate the temperature. Figure 5 is a photo taken to a specimen exposed for 15 minutes to microwaves. There are metallic iron and melted fayalite $\left(\mathrm{Fe}_{2} \mathrm{SiO}_{4}\right)$. Melting points are respectively $1537^{\circ} \mathrm{C}$ and $1217^{\circ} \mathrm{C}$, which shows that minimum temperature was about $1200^{\circ} \mathrm{C}$. Information given by thermocouples, optical pyrometry and criteria exposed above, are in good agreement between them.

Knowing that minimum temperature is about $1200^{\circ} \mathrm{C}$ we proceed to calculate the reduction curve for temperatures between $1200^{\circ} \mathrm{C}$ and $1500^{\circ} \mathrm{C}$ (close to iron melting point) and we found that all of them were practically the same. These is easy to explain, taking the reaction with $\mathrm{CO}$ it is possible to calculate that thermodynamic equilibrium makes easer to conduct reduction at low temperatures rather than high, thus simulated curves between $1100^{\circ} \mathrm{C}$ and $1500^{\circ} \mathrm{C}$ with $\mathrm{CO}$ are almost the same. We do not know the exact temperature of the pellet while it is being reduced, we just know the range, but we know how fast is the reduction in this range of temperatures. Thus, this situation makes possible to compare tests conducted with microwaves at certain power against tests conducted conventionally at certain temperature. If we take a topochemical description of the reduction process, and the temperature difference between the center and border of the pellet is small then we accept that the process is controlled by diffusion. It was described above that reduction with microwaves stops at 40\%, previous research [Hara, 1976] demonstrates that reduction is controlled by diffusion in the temperature range where this work was developed. Accepting that diffusion is the controlling step on the reduction rate, when metallic iron appears on the surface, it melts and covers the pellet, and therefore reduction stops because the reducing agent can not enter to the pellet, besides melted fayalite closes pores, porosity decreases, and this also stops the reduction. Used material is not homogeneous, then dielectric properties, responsible of heating, are different, and some places in the pellet heats at different rate. If we found that fayalite is melted we know that achieved temperature is at least $1217^{\circ} \mathrm{C}$ (Fayalite melting point). We also found that iron melts in an incipient way (Eutectic temperature of iron and carbon is $1130^{\circ} \mathrm{C}$ so temperature is still being the fayalite melting point minimum), and fayalite is well melted thus we can say that direct reduction is achieved at temperatures about $1300^{\circ} \mathrm{C}$. Reduced iron is a small film of about $0.5 \mathrm{~mm}$ covering the pellet (Figure 6), this film is melted by Joule effect and covers the pellet surface as a paint. 


\section{Factors affecting reduction rate}

From above explanation it is clear that pellet is covered with a melted iron film that does not allow the reducing agent $(\mathrm{CO})$ to reach the reaction site. When there is not this film, reduction can be conducted almost to $100 \%$. However in our case reduction can not be higher than $40 \%$ because the process is controlled by diffusion of $\mathrm{CO}$ and the melted film does not allow it to move through the reduced layer. If the microwave process is controlled by diffusion just as the conventional one is, then the reduction rate is very similar for both cases. Accepting the above sentences, then the description of the reduction process is as follows: Reduction begins outside the pellet were there is not any barrier to the reducing agent. Then we have a very thin metallic iron film that is covering the pellet. After this, reducing agent is passing through this cover to reach the interphase reaction zone. The process is slightly different for conventional and microwave reduction. In this case reduction starts outside the pellet, but it proceeds continuously because there is not barrier formation. In the microwave case, after the external part has been reduced the microwave energy heats it by Joule effect, then external layer melts and covers the pellet with liquid iron. This layer does not allow the reducing agent to pass through as easy as it is just with reduced oxide (without melt) or iron oxide.

\section{Unreacted centers versus cold centers}

It was exposed above how reduction stops due to melted iron covering the surface. Accepting that diffusion is controlling the reduction process (Figure 2), performing reduction of dust should be better than conducting reduction of pellet.

For proving this point we carried out tests on dust mixed with carbon, we found that the maximum reduction degree was not higher than the one that we obtained for pellet, meaning that there is other reason besides diffusion controlling the reduction process when it is conducted with microwave energy. This other reason could be that film of melted iron shields the pellet against the microwaves, so energy is not arriving to the center of the pellet. This argument is very important, because in this condition microwaves could not avoid the unreacted center (Figure 2). Even when in the case of dust processing the contact between regents is better (more intimate contact), final achieved 
reduction was not higher than pellet reduction. Reduction stopped due to each grain or dust particle was covered by melted iron as the pellet was. However if the argument regarding with reducing agent diffusion is true then in the case of dust the final reduction degree must be higher than in the pellet case. The answer to this apparent contradiction is that the obtained reduction degree is an average of the mixture made of dust that was exposed to the microwave field. Taking the external particles (the ones that were in contact with the crucible) of the mixture the reduction degree is higher than $90 \%$ while the particles that were at the center of the mixture were practically unreacted. Individual particles are reduced in a topochemical way an exhibit the unreacted center as the pellet does. Thus we proposed that the reduced particles at the external part of the mixture form a metallic net that shielded the rest of the mixture against the microwaves. For having a confirmation of the existence of this shield we heated carbon inside a new crucible, and compared the results with carbon heated in a crucible employed for conducting reduction of hematite dust, without cleaning the wall that is covered with metallic particles (residuals from the reduction conducted here) in a way that carbon is surrounded by these particles. Results of this comparison show that heating of carbon in the new crucible is faster than in the used one, meaning that the shield exists and even when it is supposed that microwave processing supplies energy to the whole volume [Metaxas, 1983], this assumption comes from a process were the system is small enough (specially the thickness) to have a difference between the surface and the inner part.

An advantage of the volumetric heating is that it can avoid the cold center, but when the controlling process is the mass transport (diffusion) instead of the heat supply, there will be an unreacted center that can not be avoided by microwave heating. The conclusion of Okura and Maddox [1975] regarding with the small difference between temperatures through the pellet are applicable to dust, thus in this case diffusion still being important.

\section{CONCLUSIONS}

Obtained results and the different aspects discussed above permit to put down the following conclusions: -Iron oxides absorb microwaves, therefore it is possible to supply them energy for heating or for conducting a reduction process.

-Topochemical reduction either for pellet or dust proves that the diffusion control is more important than the effect 
of the shield.

-When the reduction degree is under $40 \%$ reduction rate is practically the same for both microwave and conventional reduction.

-Pellet was heated to too high temperature and molten metallic iron covered the surface, reduction stops because melted iron avoid $\mathrm{CO}$ diffusion to the center of the pellet.

-In this case microwave processing could not avoid the unreacted centers, the process still being topochemical controlled by diffusion.

\section{REFERENCES}

Aguilar J., Kinetic constants for description of iron ore reduction, (7th International Symposium on Transport

Phenomena in Manufacturing Processes, 7, Acapulco, México 1994, 126)

Aguilar J., Fuentes R. and Viramontes R., Modelling Simul. Mater. Sci. Eng. 3, 131 (1995)

Binner J., Materials World, $\underline{1993}, 152$.

Bougdandy V. and Engell H., The reduction of iron ores, (Springer-Verlag, Berlin, 1971)

Hara Y., Tetsu-to-Hogane, 62 (3), 315 (1976)

McGill S., Walkiewicz J. and Symres G., The effects of power level on the microwave heating of selected chemicals and materials, (Microwave Processing of Materials MRS, 124, Reno Nevada 1988, 255)

Metaxas A. and Meredith R., Industrial microwave heating, (Peter peregrinus Press, London, 1983)

Okura A. and Maddox R., Tetsu-to-Hogane, 61 (9), 2151 (1975)

Standish N. and Huang W., S.I.J. International, 31 (3), 241 (1991)

Standish N. and Worner H., Journal of Microwave Power and Electromagnetic Energy 1990, 59

Tiwari P. and Bandyopadhyay D., Iron and Steelmaking, 19 (6), 464 (1992)

\section{Acknowledgements}


Authors express their gratitude to CONACYT (Mexican Council for Science and Technology) for their financial support, I. Alvarez for his help and to J. Binner for his very valuable guide and comments. 
Table I. Mean characteristics of iron ore pellet

\begin{tabular}{||l|c||}
\hline Physical & \\
\hline Pellet size (radius) & $0.6 \mathrm{~cm}$ \\
\hline Density & $4.22 \mathrm{gr} / \mathrm{cm}^{3}$ \\
\hline Weight & $3.8 \mathrm{gr}$ \\
\hline & \\
\hline $\mathrm{Chemical}^{2}$ & \\
\hline Total iron & \\
\hline $\mathrm{Fe}^{+2}$ & $66.5 \mathrm{wt} \%$ \\
\hline & \\
\hline Gangue & $0.64 \mathrm{wt} \%$ \\
\hline Gangue composition $(\mathrm{CaO}: 37 \mathrm{wt} \%, \mathrm{MgO}: 11$, & $5.3 \mathrm{wt} \%$ \\
$\left.\mathrm{SiO}_{2}: 38, \mathrm{Al}_{2} \mathrm{O}_{3}: 14\right)$ & \\
\hline \hline
\end{tabular}




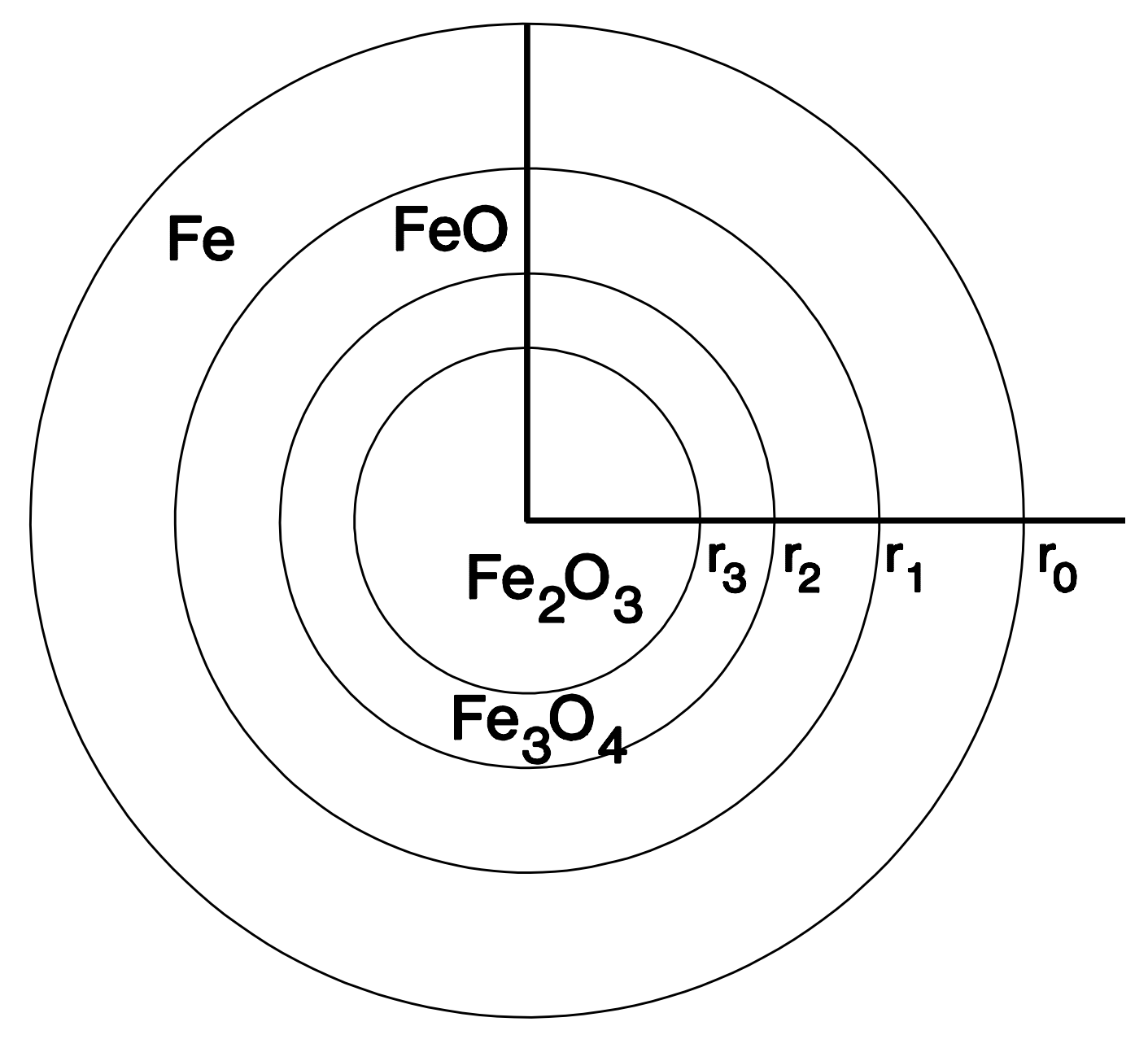


Figure 1Scheme of a pellet showing reaction interphases, $r_{1}, r_{2}$ and $r_{3}$. Carbon was in contact with the surface $r_{0}$. 
Figure 2Actual pellet showing a well defined interphase. Dark region at center is wustite surrounded by metallic iron. 


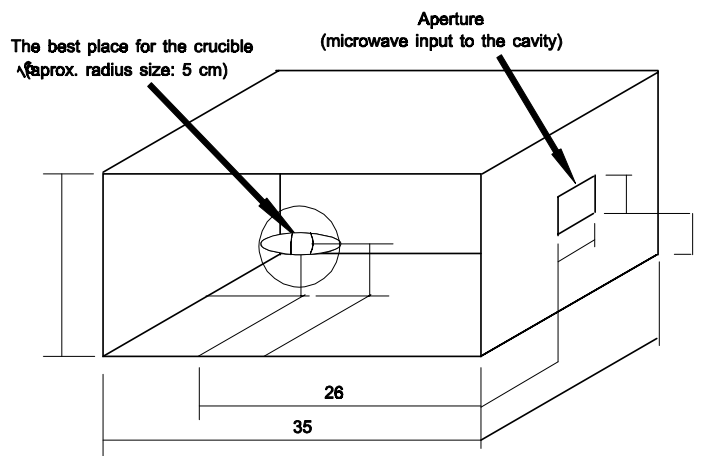

Figure 3Scheme of the cavity (distances in centimeters). The specimen was placed at the zone marked as the best. In this place was obtained the highest energy 
input.

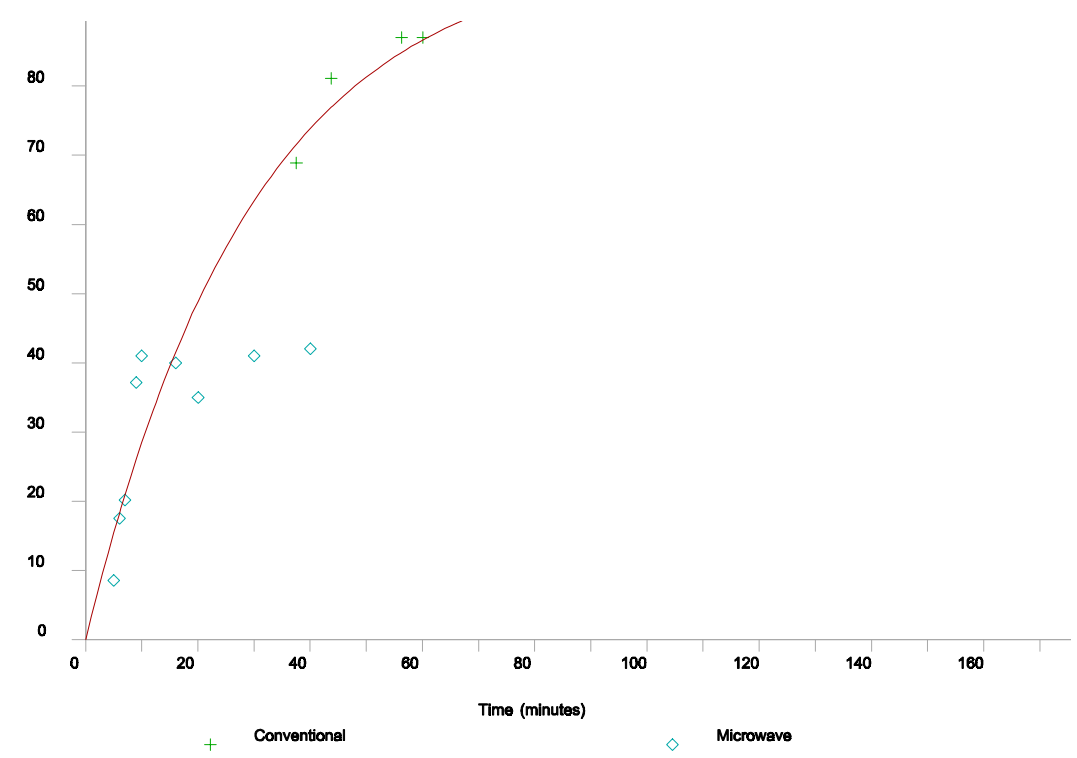

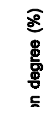

Figure 4Reduction degree against time for microwave processing at 800 watts (diamonds), and conventional heating at $1100^{\circ} \mathrm{C}$ (pluses). Solid curve is a 
calculation for temperatures between $1100^{\circ} \mathrm{C}$ and $1500^{\circ} \mathrm{C}$. Microwave processing was conducted at temperatures around $1300^{\circ} \mathrm{C}$, thus both microwave and conventional processing can be compared. 
Figure 5Specimen reduced with microwaves for 15 minutes, bright drops are melted fayalite. 

Figure 6a) Film of melted iron (SEM), b) Film of melted iron and c) a drop of iron. 